AWEJ for Translation \& Literary Studies Volume, 1 Number 3, August 2017

Pp.22-31

DOI: http://dx.doi.org/10.24093/awejtls/vol1no3.2

\title{
Translating Idiomatic Expressions from English into Arabic: Difficulties and Strategies
}

\author{
Mostafa OUALIF \\ Department of English Studies \\ Faculty of Letters and Humanities Ben M'sik, Casablanca \\ Hassan II University, Casablanca, Morocco
}

\begin{abstract}
An idiom is a form of speech or an expression that is peculiar to itself. Grammatically, it cannot be understood from the individual meanings of its elements. Culture plays an important role in the course of the idiom interpretation. Only by having a solid foundation of the culture of the target language, the translator can catch the implied meaning. It, therefore, requires enhancing cross-cultural awareness and needs open-minded understanding of the culture of the second language from different aspects. Moreover, the difference between the source language and the target language as well as variations in their cultures makes the process of translating a real challenge. The present paper tries to investigate and identify firstly some existing obstacles in the process of translating idiomatic pairs, and then suggests some theoretical strategies to overcome such difficulties. Following Baker's (1992) classification of difficulties and strategies and the related sub-categories, the findings show that there are number of factors which should be considered in order to translate idiomatic expressions correctly. The most important of such factors include socio-linguistic elements, cultural aspects, linguistic and stylistic considerations.
\end{abstract}

Key words: Arabic translation, classification of idioms, idioms, translation difficulties, translation strategies

Cite as: OUALIF, M. (2017). Translating Idiomatic Expressions from English into Arabic: Difficulties and Strategies. Arab World English Journal for Translation \& Literary Studies, 1(2). DOI: http://dx.doi.org/10.24093/awejtls/vol1no3.2 